\title{
Study of the changes in immune indexes, pathogenic characteristics and related risk factors in children with viral diarrhea
}

\author{
Di-Ying Wang, Feng Zhan, Hui-Ling Liu \\ Department of Clinical Laboratory, Changzhou Tumor Hospital Affiliated to Soochow University, Changzhou, China \\ Contributions: (I) Conception and design: DY Wang; (II) Administrative support: DY Wang; (III) Provision of study materials or patients: F Zhan; (IV) \\ Collection and assembly of data: HL Liu; (V) Data analysis and interpretation: All authors; (VI) Manuscript writing: All authors; (VII) Final approval \\ of manuscript: All authors. \\ Correspondence to: Di-Ying Wang. Department of Clinical Laboratory, Changzhou Tumor Hospital Affiliated to Soochow University, Changzhou, \\ China. Email: wdiying@163.com.
}

Background: Infectious diarrhea is a serious hazard to children under 5 years old. The causative
microorganisms are mostly viruses and bacteria, with different treatment required for each. Currently,
early clinical differential diagnosis is difficult with the available testing methods. Therefore, new and more
sensitive indicators of viral infection reflect the early stage of infection are needed.

Methods: We collected blood samples and fresh fecal samples from 100 children diagnosed with viral diarrhea who were treated in the outpatient clinic at Changzhou Tumor Hospital Affiliated to Soochow University from January 2018 to December 2020. The levels of interleukin-2 (IL-2), IL-6, tumor necrosis factor- $\alpha(\mathrm{TNF}-\alpha)$, and C-reactive protein (CRP) in serum, the erythrocyte sedimentation rate (ESR) and enterovirus were measured and compared with those in a matched healthy control group. Patients' demographic and risk factor data were collected by interviewing parents.

Results: The mean levels of IL-2, IL-6, TNF- $\alpha$, ESR, and CRP in the viral diarrhea group were higher than those in the healthy control group. Except for IL-6, the differences in inflammatory factors between groups were statistically significant $(\mathrm{P}<0.05)$. Human rotavirus $(\mathrm{HRV})$ infection was the highest. Children's hand-washing habits, weekly disinfection of toys, and vaccination were protective factors for viral diarrhea, and indoor flies were an important risk factor $(\mathrm{P}<0.05)$.

Conclusions: The serum levels of markers were significantly increased in the children with viral diarrhea. HRV was the main pathogen, and mixed infections existed. Infection control requires hand washing, regular disinfection of toys, vaccination and preventing indoor flies.

Keywords: Children; viral diarrhea; inflammatory factors; pathogenic bacteria; risk factors

Submitted Aug 17, 2021. Accepted for publication Oct 09, 2021.

doi: $10.21037 / \mathrm{tp}-21-433$

View this article at: https://dx.doi.org/10.21037/tp-21-433

\section{Introduction}

Infectious diarrhea is an intestinal disease worldwide, with high incidence rates and transmission among children (1). Diarrhea with a course of more than 2 weeks is generally called persistent diarrhea (PD) or chronic diarrhea diseases (CDD). The pathogenic microorganisms that cause diarrhea in children include bacteria, viruses, protozoa and fungi, among which viruses and bacteria are the main cause. Treatment differs, with bacterial diarrhea mainly treated with antibiotics, which are ineffective for viral diarrhea antibiotics (2). With improvements in sanitary conditions and the wide application of antibiotics, bacterial diarrhea has gradually decreased, and viruses are the most common pathogen causing diarrhea. Viral diarrhea 
accounts for a small proportion in adult diarrhea, but it is the main cause of diarrhea in children. According to the World Health Organization, viral diarrhea is one of the top 10 causes of death in the world. Approximately 1.7 billion people suffer from diarrhea every year, with a fatality rate of $\approx 9 \%$. Diarrhea is the second leading cause of death among children under 5 years old (3). Rational use of antibacterial agents and maintaining intestinal microecological balance are the key to the prevention and treatment of infantile diarrhea, at present, the differential diagnosis of infectious diarrhea mainly relies on stool culture and related inspections (4), but the slow process and the low positive rates of bacteriological and virus antigen testing do not meet the need for early clinical differential diagnosis (5). New and more sensitive indicators of viral infection, especially indicators that reflect the early stage of infection, are being investigated. Interleukin-2 (IL-2), IL-6, tumor necrosis factor- $\alpha$ (TNF- $\alpha$ ), C-reactive protein (CRP) and the erythrocyte sedimentation rate (ESR) are all used as markers of early inflammation and are involved in the immune response (6-9), However, their application value in the management of viral diarrhea is unclear.

The purpose of this study was to analyze the changes in the serum levels of IL-2, IL-6, TNF- $\alpha$, and in the ESR in children with viral diarrhea, as well as the etiological characteristics and disease-related risk factors, to provide references for the diagnosis, prevention and control of pediatric viral diarrhea.

We present the following article in accordance with the STROBE reporting checklist (available at https://dx.doi. org/10.21037/tp-21-433).

\section{Methods}

\section{Research subjects}

From January 2018 to December 2020, children with diarrhea aged 40 days to 60 months were selected from the outpatient department of Changzhou Tumor Hospital Affiliated to Soochow University. Among them, 100 children diagnosed with viral diarrhea by laboratory tests were selected, and 100 healthy children of the same sex and age in the hospital during the same time period were selected as the controls using 1:1 pairing. Viral diarrhea was clinically defined as defecation $\geq 3$ times per day with a change in stool characteristics, and was confirmed by laboratory tests as human rotavirus (HRV), norovirus (Nov), human astrovirus (HAstV), human adenovirus (HAdV) or mixed infection. Informed consent was given by parents or guardians of the children and clinical data were provided (Figure 1). All procedures performed in this study involving human participants were in accordance with the Declaration of Helsinki (as revised in 2013). The study was approved by the Ethics Committee of Changzhou Tumor Hospital Affiliated to Soochow University (No.: 2017332).

\section{Detection of inflammatory factors}

Fasting venous blood was collected from the children in both groups in the morning, and serum was separated. IL2, IL-6 and TNF- $\alpha$ were detected by ELISA kits (Shanghai Kaibo Biological Co., Ltd.). CRP was detected by Hitachi 7060 automatic biochemical analyzer using the appropriate detection reagent (Shanghai Rongsheng Biotechnology Co., Ltd.). ESR was measured by automatic analyzer (Shanghai Xunda Medical Instrument Company). All measurements are carried out in strict accordance with the manufacturers' instructions. The differences in the serum levels of inflammatory factors were compared between the two groups.

\section{Detection of enteroviruses}

A diarrhea virus joint detection system (Beijing Bohui) was used. Following the manufacturer's instructions.

\section{Risk factor investigation}

The risk factors in the case and control groups were investigated by a face-to-face questionnaire that included (I) baseline clinical information (child's name, sex, date of birth, place of residence, whether received HRV, etc.); (II) family history: parents' education level, home environment (type of drinking water, pet keeping, toy disinfection, indoor flies), and hygiene habits (disinfection of tableware, kitchen knives and boards; cooking hygiene, hand-washing, etc.).

\section{Statistical analysis}

SPSS 22.0 (SPSS Inc., Chicago, IL, USA) was used for statistical analysis. Measurement data with a normal distribution are expressed as $\bar{x} \pm \mathrm{s}$. The $t$-test of independent samples was used for comparison between groups. The Chisquare test was used for comparison of count data between groups. The risk factors of viral diarrhea were analyzed by univariate analysis and logistic regression model. $\mathrm{P}<0.05$ 


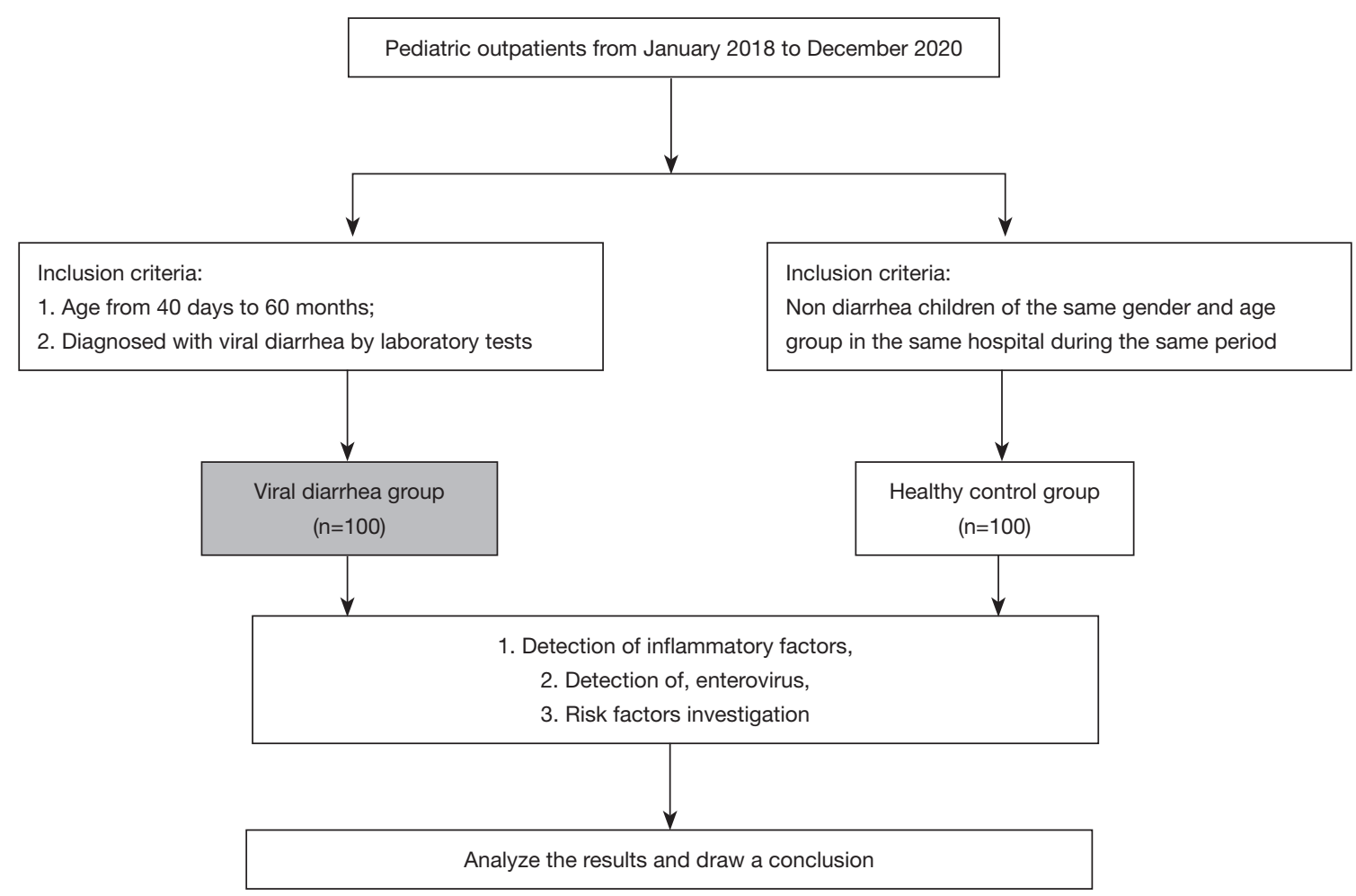

Figure 1 Study flowchart.

was considered a statistically significant difference.

\section{Results}

\section{Levels of inflammatory factors}

The levels of IL-2, IL-6, TNF- $\alpha$, ESR, and CRP in the viral diarrhea group were respectively $50.38 \pm 16.45 \mathrm{pg} / \mathrm{mL}$, $11.80 \pm 6.31 \mathrm{pg} / \mathrm{mL}, 67.55 \pm 14.08 \mathrm{pg} / \mathrm{mL}, 22.11 \pm 10.44 \mathrm{~mm} / \mathrm{h}$, and $11.28 \pm 7.22 \mathrm{mg} / \mathrm{L}$ versus $25.20 \pm 8.75 \mathrm{pg} / \mathrm{mL}, 10.33 \pm$ $4.61 \mathrm{pg} / \mathrm{mL}, 56.24 \pm 10.42 \mathrm{pg} / \mathrm{mL}, 7.02 \pm 3.11 \mathrm{~mm} / \mathrm{h}$, and $5.01 \pm 2.44 \mathrm{mg} / \mathrm{L}$ in the healthy control group. Except for IL-6, the differences in the levels of inflammatory factors were statistically significant between the two groups $(\mathrm{P}<0.05)$ (Table 1).

\section{Types and proportions of viral infections}

Among the 100 fecal samples, 92 were single virus-positive samples (92\%), and 8 were mixed infections (8\%); among the single-virus infections, HRV infection was the highest, with a total of 63 cases (63\%). Mixed infections of HRV+ $\mathrm{NoV}$ ( 3 cases) and HRV+ HastV (3 cases) were the most common (Tables 2,3).

\section{Risk factor analysis}

\section{Univariate analysis}

Univariate analysis was performed for the factors related to viral diarrhea in children, and the results are shown in Table 4. Incidence was related to both the children's and the cooks' hand-washing habits, daily disinfection of tableware, weekly disinfection of toys, vaccination, whether separate cutting boards were used for raw and cooked food, and the presence of flies indoors $(\mathrm{P}<0.05)$.

\section{Multivariate analysis}

The results of multivariate logistic regression analysis are shown in Table 5. Children's hand-washing habits, weekly disinfection of toys, and vaccinations were protective factors $(\mathrm{P}<0.05)$. Indoor flies were an important risk factor for childhood viral diarrhea $(\mathrm{P}<0.05)$.

\section{Discussion}

The human immune system includes immune organs 
Table 1 Comparison of immune indexes between the two groups

\begin{tabular}{|c|c|c|c|c|c|c|}
\hline Group & $\mathrm{n}$ & IL-2 (pg/mL) & IL-6 (pg/mL) & TNF- $\alpha(p g / m L)$ & $\operatorname{ESR}(\mathrm{mm} / \mathrm{h})$ & $\mathrm{CRP}(\mathrm{mg} / \mathrm{L})$ \\
\hline Healthy control group & 100 & $25.20 \pm 8.75$ & $10.33 \pm 4.61$ & $56.24 \pm 10.42$ & $7.02 \pm 3.11$ & $5.01 \pm 2.44$ \\
\hline $\mathrm{F}$ & & 27.089 & 14.568 & 7.875 & 90.605 & 96.034 \\
\hline$P$ value & & 0.001 & 0.061 & 0.001 & 0.001 & 0.001 \\
\hline
\end{tabular}

IL-2, interleukin-2; IL-6, interleukin-6; TNF- $\alpha$, tumor necrosis factor- $\alpha$; ESR, the erythrocyte sedimentation rate; CRP, C-reactive protein.

Table 2 Fecal enterovirus detection

\begin{tabular}{lcc}
\hline Pathogen & No. of positive cases & Constituent ratio* $(\%)$ \\
\hline HRV & 63 & 63 \\
NoV & 25 & 25 \\
HAstV & 12 & 12 \\
HAdV & 8 & 8 \\
\hline
\end{tabular}

*, because of mixed infection, the total positive number is not equal to $100 \%$. HRV, human rotavirus; NoV, norovirus; HAstV, human astrovirus; HAdV, human adenovirus.

Table 3 Fecal enterovirus mixed infection

\begin{tabular}{lcc}
\hline Mixed infection & N & Constituent ratio (\%) \\
\hline HRV + NoV & 3 & 3 \\
HRV + HAstV & 3 & 3 \\
NoV + HAstV & 1 & 1 \\
HRV + HAdV & 1 & 1
\end{tabular}

HRV, human rotavirus; NoV, norovirus; HAstV, human astrovirus; HAdV, human adenovirus.

such as bone marrow and the thymus, immune cells such as lymphocytes, and immune active molecules such as antibodies and immunoglobulins. It is the basis for the body to recognize and resist foreign pathogens and maintain physiological functions and homeostasis (10). The development of both the immune system and digestive system of infants is not mature, and the level of immune antibody from mothers gradually declines (11), leading to increased occurrence of infectious diarrhea. Of the variety of causative pathogens, bacterial and viral infections are most common, especially viruses. It is currently believed that HRV is the most common cause of both viral diarrhea and acute gastroenteritis in children. Approximately 140 million children worldwide have HRV diarrhea each year, of which $\approx 25$ million are outpatients and 2 million are visits. Due to the lack of effective symptomatic treatment, the number of deaths of children under 5 caused by HRV each year is about 527,000 , mainly in developing countries $(12,13)$. $\mathrm{NoV}$ is the second most common pathogen causing acute gastroenteritis in children, but with increasing HRV vaccination rates in some countries and regions, $\mathrm{NoV}$ is becoming the main cause of viral diarrhea in children in some regions $(14,15)$. HAstV infection is widespread around the world. Due to different geographic locations and detection methods, the detection rate of $\mathrm{HAstV}$ varies between $2 \%$ and $9 \%$. For example, the detection rate of HAstV viral diarrhea in South Korea is only $1.3 \%$ (16), $0.6 \%$ in Ho Chi Minh City, Vietnam (17), and $13.5 \%$ in Brazil (18). In the present study, 92 single virus-positive samples (92\%) were detected, and 8 cases of mixed infection (8\%). HRV infection was the highest single-virus infection, with a total of 63 cases $(63 \%)$, followed by $\mathrm{NoV}$ infection, with a total of 25 cases $(25 \%)$, consistent with previous domestic research $(19,20)$.

In this study, analysis of serum indicators showed that IL-2 in the viral diarrhea group was significantly increased, indicating immune dysfunction. This is because the virus invades the jejunal villi epithelial cells and stimulates their large secretion $\mathrm{T}$ lymphocytes, and $\mathrm{T}$ lymphocyte activation can trigger the activation of the $\mathrm{NF}-\kappa \mathrm{B}$ pathway and upregulate the expression of IL-2. As a cytotoxic inflammatory factor, the increased level of IL-2 not only means autoimmunity is restricted, but also causes enhanced local inflammation and destruction of the intestinal barrier system $(21,22)$.

TNF- $\alpha$ is an important member of the inflammatory cytokine network. It has strong inflammatory activity and can directly act on vascular endothelial cells to increase their permeability, leading to a large amount of intestinal wall exudation and excessive secretion of TNF- $\alpha$, which can enter the blood circulation and cause systemic reactions, such as fever, because TNF- $\alpha$ is an endogenous pyrogen and 
Table 4 Single-factor analysis results of children with viral diarrhea

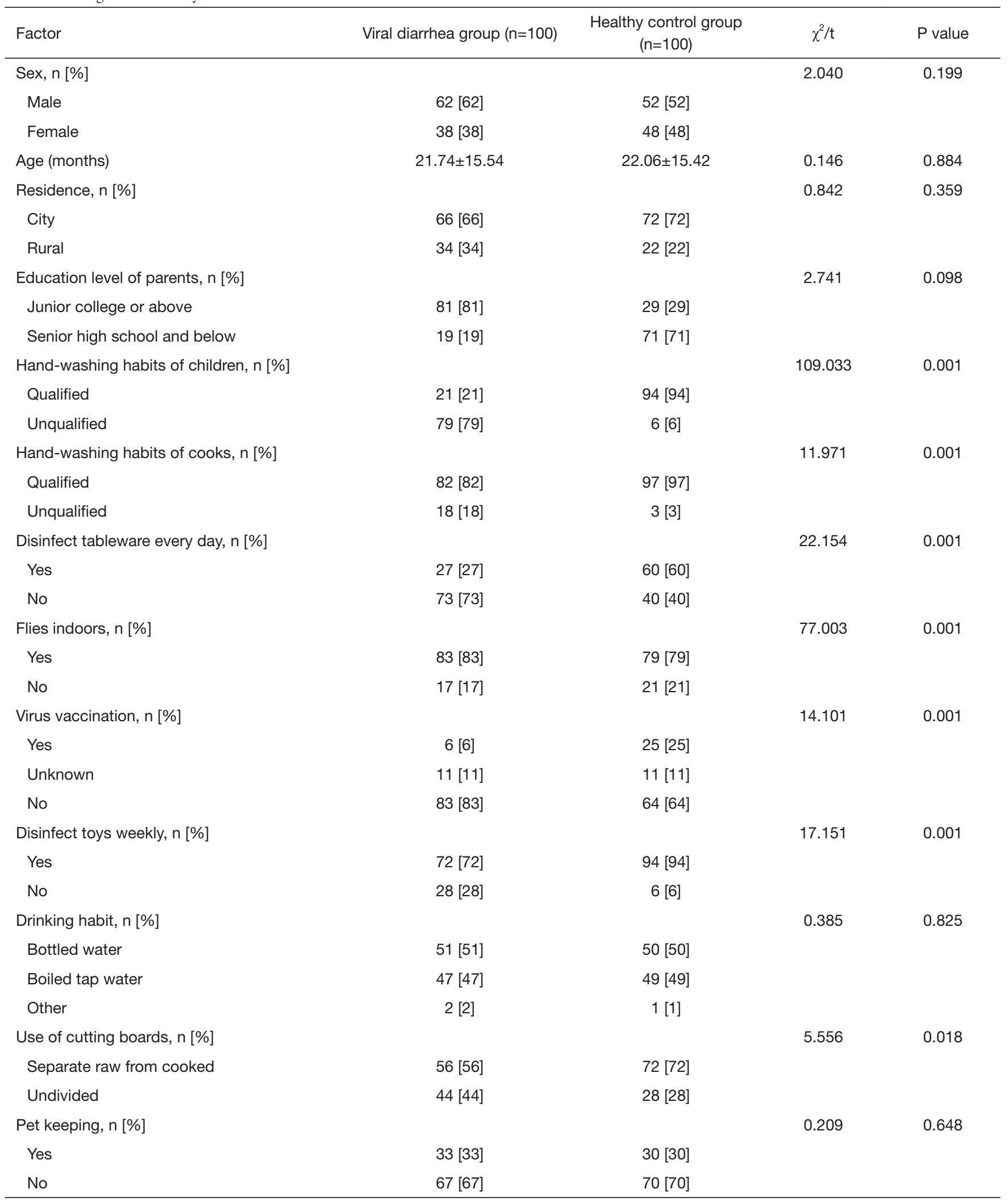


Table 5 Results of multivariate logistic regression analysis of children with viral diarrhea

\begin{tabular}{lcccccc}
\hline Related factor & $\beta$ & SE & Ward & OR & $95 \% \mathrm{Cl}$ & $\mathrm{P}$ value \\
\hline Hand-washing habits of children & 4.131 & 0.705 & 34.329 & 62.240 & $15.629-247.864$ & 0.001 \\
Hand-washing habits of cooks & 2.048 & 1.360 & 2.269 & 7.754 & $0.539-111.442$ & 0.132 \\
Disinfect tableware every day & 1.000 & 0.575 & 3.031 & 2.720 & $0.882-8.388$ & 0.082 \\
Flies indoors & -3.130 & 0.637 & 24.181 & 0.044 & $0.013-0.152$ & 0.001 \\
Virus vaccination & 2.656 & 1.246 & 4.541 & 14.240 & $1.237-163.871$ & 0.033 \\
Disinfect toys weekly & 1.868 & 0.884 & 4.465 & 6.475 & $1.145-36.618$ & 0.035 \\
Use of separate cutting boards & 1.216 & 0.614 & 1.792 & 3.375 & $0.860-13.252$ & 0.181 \\
\hline
\end{tabular}

acts on the hypothalamus. It can also cause monocytes and vascular endothelial cells to secrete large amounts of IL-1 and IL-6, which enter the blood circulation and enhance the cytokine-mediated inflammatory response. In this study, the level of serum TNF- $\alpha$ in the viral diarrhea group was significantly higher than in the healthy control group. A study found that the level of TNF- $\alpha$ in severe diarrhea was significantly higher than that in the mild group, indicating that TNF- $\alpha$ is the main pro-inflammatory factor in viral infections without antiviral effect (23).

CRP is a normal protein component in human plasma at very low levels, but is also an acute-phase protein, with levels closely related to inflammation and tissue damage. When injuries or inflammation occur, the synthesis and decomposition rate of CRP in the liver increases. CRP is not affected by factors such as sex, age, etc. (24), Moreover, detection is convenient and results can be obtained quickly. Therefore, CRP can be used as a measure of the acute stage of infection, and our test results showed that the difference between the viral diarrhea and healthy control groups was highly significant $(\mathrm{P}<0.001)$.

ESR is a non-specific marker of tissue inflammation or destruction, especially potential (latent) disease, which is used in the diagnosis of malignant tumor. Monitoring the ESR can also be used to understand the progress of a disease, guide prognosis, and to evaluate a person's health status. It reflects the aggregation of fibrinogen and immunoglobulin. In acute inflammation, acute-phase substances (i.e., ESR, fibrinogen, etc.) increase rapidly, and their components can promote cell aggregation more or less, so ESR can be accelerated 2-3 days after inflammation (25). Our test results showed that the difference between the viral diarrhea and healthy control groups was highly significant $(\mathrm{P}<0.001)$.

\section{Study limitations}

There was no analysis of the changes in inflammatory factors during remission, no research on the influence of the levels of inflammatory factor and pathogen distribution on clinical symptoms, and no virus testing for patients in different seasons and of different ages. We will carry out supplementary research on these aspects in the future.

\section{Conclusions}

Based on our analysis, the factors associated with viral diarrhea can be summarized into three aspects: personal hygiene, family environmental hygiene and vaccination. As the main pathogens of viral diarrhea (e.g., HRV), mainly enter patients through contaminated food or utensils, good environmental and hygiene habits are effective measures to reduce the occurrence of viral diarrhea, which is consistent with previous research results of diarrhea risk factors (26). Vaccination is also a protective for viral diarrhea (27).

\section{Acknowledgments}

Funding: None.

\section{Footnote}

Reporting Checklist: The authors have completed the STROBE reporting checklist. Available at https://dx.doi. org/10.21037/tp-21-433

Data Sharing Statement: Available at https://dx.doi. org/10.21037/tp-21-433 
Conflicts of Interest: All authors have completed the ICMJE uniform disclosure form (available at https://dx.doi. org/10.21037/tp-21-433). The authors have no conflicts of interest to declare.

Etbical Statement: The authors are accountable for all aspects of the work in ensuring that questions related to the accuracy or integrity of any part of the work are appropriately investigated and resolved. All procedures performed in this study involving human participants were in accordance with the Declaration of Helsinki (as revised in 2013). The study was approved by the Ethics Committee of Changzhou Tumor Hospital Affiliated to Soochow University (NO.:2017332) Informed consent was given by parents or guardians of the children.

Open Access Statement: This is an Open Access article distributed in accordance with the Creative Commons Attribution-NonCommercial-NoDerivs 4.0 International License (CC BY-NC-ND 4.0), which permits the noncommercial replication and distribution of the article with the strict proviso that no changes or edits are made and the original work is properly cited (including links to both the formal publication through the relevant DOI and the license). See: https://creativecommons.org/licenses/by-nc-nd/4.0/.

\section{References}

1. Gong Z, Zeng M, Zhu Qg, et al. Molecular epidemiology of group A rotavirus diarrhea in children in Shanghai; 30:288-92.

2. Zeng M, Zhang $\mathrm{Y}$, Zhu Q, et al. Clinical and molecular epidemiology of rotavirus in children with communityacquired and hospital-acquired diarrhea in Shanghai, China. Pediatr Infect Dis J 2010;29:177-80.

3. Liu L, Oza S, Hogan D, et al. Global, regional, and national causes of child mortality in 2000-13, with projections to inform post-2015 priorities: an updated systematic analysis. Lancet 2015;385:430-40.

4. Lesanu G, Becheanu CA, Vlad RM, et al. Clinical characteristics of rotavirus diarrhea in hospitalized Romanian infants. Pediatr Infect Dis J 2013;32:89-91.

5. Qu M, Deng Y, Zhang X, et al. Etiology of acute diarrhea due to enteropathogenic bacteria in Beijing, China. J Infect 2012;65:214-22.

6. Li A, Zhang C, Pang P, et al. Changes of creatine phosphokinase and high sensitivity C-reactive protein in children with group A rotavirus. Chinese Journal of nosocomial infection, 2010; 20:50-2.

7. Decaluwe H, Harrison LM, Mariscalco MM, et al. Procalcitonin in children with Escherichia coli O157:H7 associated hemolytic uremic syndrome. Pediatr Res 2006;59:579-83.

8. Korczowski B, Szybist W. Serum procalcitonin and C-reactive protein in children with diarrhoea of various aetiologies. Acta Paediatr 2004;93:169-73.

9. Narváez CF, Franco MA, Angel J, et al. Rotavirus differentially infects and polyclonally stimulates human B cells depending on their differentiation state and tissue of origin. J Virol 2010;84:4543-55.

10. Brodin P, Jojic V, Gao T, et al. Variation in the human immune system is largely driven by non-heritable influences. Cell 2015;160:37-47.

11. Strömbeck A, Lundell AC, Nordström I, et al. Earlier infantile immune maturation is related to higher DTP vaccine responses in children. Clin Transl Immunology 2016;5:e65.

12. Parashar UD, Burton A, Lanata C, et al. Global mortality associated with rotavirus disease among children in 2004. J Infect Dis 2009;200 Suppl 1:S9-s15.

13. Parashar UD, Hummelman EG, Bresee JS, et al. Global illness and deaths caused by rotavirus disease in children. Emerg Infect Dis 2003;9:565-72.

14. Boni-Cisse C, Meite S, Mlan AB, et al. Genotypic characterization of rotavirus in children under 5 years circulating in Côte D'Ivoire from 2010 to 2013. Virol J 2018;15:78.

15. Li YT, Xu H, Ye JZ, et al. Efficacy of Lactobacillus rhamnosus GG in treatment of acute pediatric diarrhea: A systematic review with meta-analysis. World J Gastroenterol 2019;25:4999-5016.

16. Jeong AY, Jeong HS, Jo MY, et al. Molecular epidemiology and genetic diversity of human astrovirus in South Korea from 2002 to 2007. Clin Microbiol Infect 2011;17:404-8.

17. Nguyen TA, Yagyu F, Okame M, et al. Diversity of viruses associated with acute gastroenteritis in children hospitalized with diarrhea in Ho Chi Minh City, Vietnam. J Med Virol 2007;79:582-90.

18. Sebire NJ, Malone M, Shah N, et al. Pathology of astrovirus associated diarrhoea in a paediatric bone marrow transplant recipient. J Clin Pathol 2004;57:1001-3.

19. Ren B, Zhao R, Wang N, et al. Study on etiology and epidemic characteristics of viral diarrhea in hospitalized infants under 5 years old in Taiyuan City in 2012. Journal of practical medical technology, 2013; 20:1269-71.

20. Wang F, Jin M, Li D, et al. Molecular epidemiology of 
viral diarrhea in children at ages of less than 5 years in Lanzhou City, Gansu Province, China in 2017. Chinese Journal of Biologicals 2019;32:1102-7.

21. Maffey L, Vega CG, Parreño V, et al. Controlling Rotavirus-associated diarrhea: Could single-domain antibody fragments make the difference? Rev Argent Microbiol 2015;47:368-79.

22. O'Ryan GM, Ashkenazi-Hoffnung L, O'Ryan-Soriano MA, et al. Management of acute infectious diarrhea for children living in resource-limited settings. Expert Rev Anti Infect Ther 2014;12:621-32.

23. Wehkamp J, Götz M, Herrlinger K, et al. Inflammatory Bowel Disease. Dtsch Arztebl Int 2016;113:72-82.

24. Holtman GA, Lisman-van Leeuwen Y, Reitsma JB, et al.

Cite this article as: Wang DY, Zhan F, Liu HL. Study of the changes in immune indexes, pathogenic characteristics and related risk factors in children with viral diarrhea. Transl Pediatr 2021;10(10):2544-2551. doi: 10.21037/tp-21-433
Noninvasive Tests for Inflammatory Bowel Disease: A Meta-analysis. Pediatrics 2016;137.

25. Lapić I, Padoan A, Bozzato D, et al. Erythrocyte Sedimentation Rate and C-Reactive Protein in Acute Inflammation. Am J Clin Pathol 2020;153:14-29.

26. Mou X, Qu W, Liu J. Epidemiological characteristics of rotavirus in Yantai city from 2017 to 2019. Preventive medicine forum 2021; 27:336-8.

27. Zhou $Y$, Zhao Q, Ni Z, et al. Investigation on risk factors of viral diarrhea in infants under 5 years old in Yuxi City. China primary health care 2019; 33:65-7.

(English Language Editor: K. Brown) 